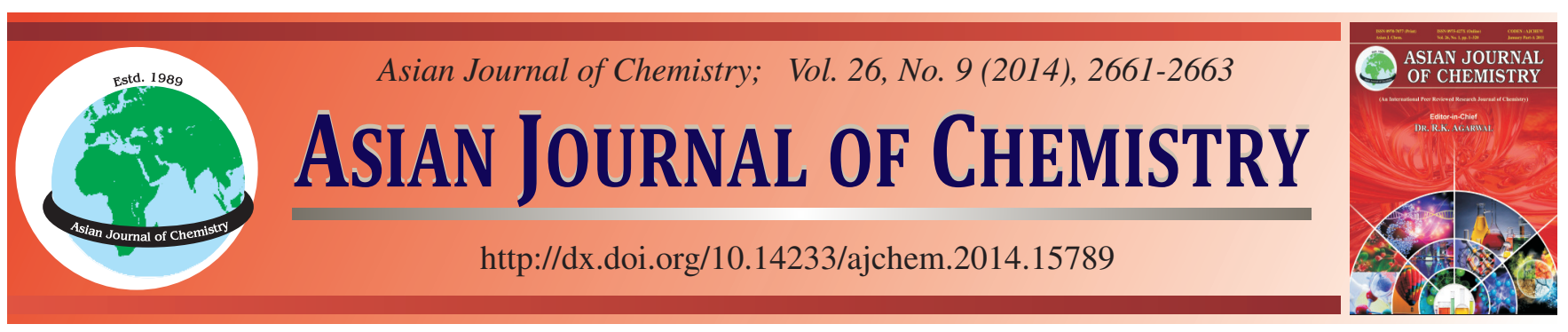

\title{
Evaluation of Essential Oil from Common Medicinal Plants Against Culex quinquefasciatus Larvae (Diptera: Culicidae) in Pakistan
}

\author{
Sabiha Fazal, Farkhanda Manzoor ${ }^{*}$ and Asma Abdul Latif
}

Department of Zoology, Lahore College for Women University, Lahore, Pakistan

*Corresponding author: E-mail: doc_farkhanda@yahoo.com

\begin{abstract}
Five essential oils from various parts of plant species E. citriodora, P. harmala, A. indica, C. nucifera and Turpentine were investigated for their larvicidal properties against Culex quinquefasciatus (Say). Twenty late $3^{\text {rd }}$ instar larvae of $C x$. quinquefasciatus were collected from the insectaria and exposed to different concentrations of essential oils ranging from 1.95-1000 ppm. The larval mortality was observed after $24 \mathrm{~h}$ under the laboratory conditions. Results showed that the highest larvicidal activity was in Turpentine oil against $C x$. quinquefasciatus (Say) with the $\mathrm{LC}_{50}$ values $63.8 \mathrm{ppm}$. However the $\mathrm{LC}_{50}$ values for $E$. citriodora, P. harmala, $A$. indica, $C$. nucifera were $165.51,85.91,207.56$ and $338.58 \mathrm{ppm}$, respectively. It was concluded that five essential oils which were distilled from $E$. citriodora, $P$. harmala, A. indica, C. nucifera and Turpentine had remarkable larvicidal properties, which may be considered as a potent source for the production of natural larvicides which would be environmentally safe and alternative to synthetic insecticides.
\end{abstract}

Keywords: Essential oil, Medicinal plants, Culex quinquefasciatus Larvae.

\section{INTRODUCTION}

A major cause of illness and death throughout the world are the diseases which are transmitted by insects ${ }^{1}$. According to public health the most important groups of insects are mosquitoes. They transmit a number of diseases such as filariasis, malaria, Japanese encephalitis, dengue, etc. over two billion people are in danger because of mosquito born diseases especially in tropical countries ${ }^{2}$. It is a strong winged domestic species seen all over the world and around human dwellings. Adult $C x$. quinquefasciatus (Say) is approximately 3.96 to 4.25 $\mathrm{mm}$ in length ${ }^{3}$. The species is highly anthropophlic (they prefer human blood). The females will take multiple blood meals while male survive only on sugar meals. The prevention of mosquito breeding through the use of synthetic larvicides is the most effective way to get rid off these mosquitoes ${ }^{4}$. The larvicides continue to be applied for controlling mosquitoes but many of these chemicals are toxic to human, animal and plant life and resistance can be problematic in regulating the control. Therefore, researchers are currently exploiting natural substances to be used as insecticides for controlling larval stage of mosquitoes ${ }^{5,6}$.

Biopesticides are excellent substitute to synthetic pesticides because of their minor toxicity to humans, insignificant environmental pollution and other benefits ${ }^{7}$. Present study was carried out with the objective to evaluate the comparative efficacy of some essential oils against Lymphatic filariasis causing mosquito $C x$. quinquefasciatus.

\section{EXPERIMENTAL}

All tests were conducted by using larvae of mosquito, Cx. quinquefasciatus were taken from insectaria. The identification was based on following morphological characters.

To evaluate the larvicidal activity of essential oils following plants were used viz., Eucalyptus citriodora (Eucalyptus), Peganum harmala (Harmal), Azadirachta indica (Neem), Cocos nucifera (Coconut), Turpentine (Tarpeen).

Extraction of essential oils: Oils were extracted by steam distillation (Reverse Dean-Stark method).

Evaluation of essential oils with respect to their larvicidal properties: The test was conducted in Entomology Research laboratory, Zoology department, Lahore College for Women University at room temperature. The experimental plant essential oils were used in trials. Three replicates of each oil were prepared by dissolving the suitable amount of oil in distilled water to produce stock solution by using the acetone. Only $2 \mathrm{~mL}$ acetone and $198 \mathrm{~mL}$ of distilled water were used in the control replicates ${ }^{8}$. The stock solution of $1000 \mathrm{ppm}$ was prepared by dissolving $1 \mathrm{~mL}$ of essential oil in $1000 \mathrm{~mL}$ of distilled water using $2 \mathrm{~mL}$ of $100 \%$ acetone. This solution was used to prepare the serial dilutions of target oil in concentration of $500,250,125,62.5,31.25,15.62,7.81,3.90,1.90$, 
$0.97 \mathrm{ppm}$ through dilution of the stock solution with distilled water; three replicates of each concentration were made. In addition to three replicates, the control contains $0 \mathrm{ppm}$ of oil, $2 \mathrm{~mL}$ of $100 \%$ acetone and distilled water.

Bioassay of oil solution: Each replicate containing 200 $\mathrm{mL}$ of the described oil solution was placed in a $250 \mathrm{~mL}$ of beakers. Twenty late $3^{\text {rd }}$ instars larvae of culex mosquitoes were transferred into each beaker ${ }^{9}$. After that, the beakers were left on the laboratory table for $24 \mathrm{~h}$. The number of dead larvae in each beaker was counted after $24 \mathrm{~h}$. Twenty $3^{\text {rd }}$ instar larvae of respective specie were transferred to each beaker. The number of dead larvae in each beaker was counted after $24 \mathrm{~h}$ of contact at room temperature. The larvae were considered dead if they were immobile and unable to reach the water surface.

Calculation of $\mathbf{L C}_{\mathbf{5 0}}$ and statistical analysis: Insect mortality data were corrected by Abbott's formula (1925), $\mathrm{LC}_{50}$ values (the concentration at which $50 \%$ of the larvae were immobilized) were calculated by probit analysis using PROBIT software Statistical Package for the Social Sciences while randomized complete blocked design ANOVA were used to detect the significant differences between the treatments in all tests. Means were compared with Duncan's multiple range tests.

\section{RESULTS AND DISCUSSION}

Public awareness and resulting environmental agencies ruling led to the removal of some synthetic insecticides from the market ${ }^{10}$. There are number of alternatives to using chemical pesticides for mosquito larval control. One of the alternative methods is the use of essential oils. In the view of recently increased interest in developing plant origin insecticides as an alternative to chemical insecticide, this study was undertaken to access the toxicant potential of the five essential oils that are Turpentine, P. harmala, A. indica, E. citriodora and C. nucifera against mosquito species $C x$. quinquefasciatus (Say).
The percentage mortality of mosquito species $C x$. quinquefasciatus when exposed to different concentrations of five essential oils i.e., E. citriodora, P. harmala, A. indica, $C$. nucifera and Turpentine after $24 \mathrm{~h}$ exposure are shown in Table-1. The $\mathrm{LC}_{50}$ values and relative toxicity of these five essential oils are given in Table- 2 .

Turpentine oil treatment: Table-1 revealed the percentage mortality of larvae of $C x$. quinquefasciatus (Say) when exposed to different concentrations of Turpentine oil. The \% mortality for Cx. quinquefasciatus (Say) after $24 \mathrm{~h}$ of treatment was $0,0,10,30,30,45,55,75,100$ and $100 \%$ at concentrations of $1.95,3.90,7.81,15,62,31.25,62.50,125.00,250.00,500.00$ and $1000.00 \mathrm{ppm}$, respectively. The $\mathrm{LC}_{50}$ value (Table-2) for Cx. quinquefasciatus (Say) was 63.8 with lower and upper $95 \%$ confidence limits as 402.530 and 1558.19 , respectively. Analysis of variance revealed that concentrations of Turpentine oil tested against $C x$. quinquefasciatus (Say) were significantly different among all treatments $(F=3.233, \mathrm{df}=6,3 ; \mathrm{p}<0.0001)$.

Peganum harmala oil treatment: Table-1 revealed the percentage mortality of larvae of $C x$. quinquefasciatus (Say) when exposed to different concentrations of Peganumharmala oil. The \% mortality for Cx. quinquefasciatus (Say) after $24 \mathrm{~h}$ of treatment was $0,0,10,10,25,45,55,75,85$ and $100 \%$ at concentrations of $1.95,3.90,7.81,15,62,31.25,62.50,125.00$, $250.00,500.00$ and $1000.00 \mathrm{ppm}$, respectively. Table- 2 showed the $\mathrm{LC}_{50}$ value for $C x$. quinquefasciatus (Say) was 85.91 with lower and upper $95 \%$ confidence limits as 533.45 and 2171.539 , respectively. Analysis of variance revealed that concentrations of $P$. harmala oil tested against $C X$. quinquefasciatus (Say) were significantly different among all treatments $(\mathrm{F}=$ 8237, df $=7,2 ; \mathrm{p}<0.0001$ ).

Cocos nucifera oil treatment: Table-1 revealed the percentage mortality of larvae of $C x$. quenquefasciatus (Say) when exposed to different concentrations of $C$. nucifera oil. The \% mortality for $C x$. quinquefasciatus (Say) after $24 \mathrm{~h}$ of treatment

\begin{tabular}{|c|c|c|c|c|c|c|c|}
\hline \multirow{3}{*}{$\begin{array}{l}\text { S. } \\
\text { No }\end{array}$} & \multicolumn{7}{|c|}{$\begin{array}{l}\text { TABLE-1 } \\
\text { PERCENTAGE MORTALITY } \pm \text { SE OF Culex quinquefasciatus WHEN EXPOSED TO } \\
\text { DIFFERENT CONCONTRATIONS OF FIVE ESSENTIAL OILS AND CONTROL UNIT }\end{array}$} \\
\hline & \multirow{2}{*}{$\begin{array}{c}\text { Concentration } \\
(\mathrm{ppm})\end{array}$} & \multicolumn{5}{|c|}{$\%$ Mortality \pm SE } & \multirow[b]{2}{*}{ Control } \\
\hline & & Turpentine oil & P. harmala oil & Cocos nucifera oil & Azadiracta indica oil & Eucalyptus citriodora oil & \\
\hline 1 & 1.95 & $0.0 \pm 0.0$ & $0.0 \pm 0.0$ & $0.0 \pm 0.0$ & $0.0 \pm 0.0$ & $0.0 \pm 0.0$ & $0.0 \pm 0.0$ \\
\hline 2 & 3.90 & $0.0 \pm 0.0$ & $0.0 \pm 0.0$ & $0.0 \pm 0.0$ & $0.0 \pm 0.0$ & $0.0 \pm 0.0$ & $0.0 \pm 0.0$ \\
\hline 3 & 7.81 & $10.0 \pm 0.5$ & $10.0 \pm 0.5$ & $0.0 \pm 0.0$ & $0.0 \pm 0.0$ & $0.0 \pm 0.0$ & $0.0 \pm 0.0$ \\
\hline 4 & 15.62 & $30.0 \pm 0.5$ & $10.0 \pm 0.5$ & $0.0 \pm 0.0$ & $5.0 \pm 0.0$ & $0.0 \pm 0.0$ & $0.0 \pm 0.0$ \\
\hline 5 & 31.25 & $30.0 \pm 0.0$ & $25.0 \pm 0.5$ & $0.0 \pm 0.0$ & $5.0 \pm 0.0$ & $5.0 \pm 0.0$ & $0.0 \pm 0.0$ \\
\hline 6 & 62.50 & $45.0 \pm 0.0$ & $45.0 \pm 0.0$ & $10.0 \pm 0.0$ & $15.0 \pm 0.5$ & $20.0 \pm 0.5$ & $0.0 \pm 0.0$ \\
\hline 7 & 125.00 & $55.0 \pm 0.5$ & $55.0 \pm 0.0$ & $15.0 \pm 0.0$ & $30.0 \pm 0.5$ & $40.0 \pm 0.5$ & $0.0 \pm 0.0$ \\
\hline 8 & 250.00 & $75.0 \pm 0.5$ & $75.0 \pm 0.0$ & $25.0 \pm 0.5$ & $55.0 \pm 0.5$ & $65.0 \pm 0.5$ & $0.0 \pm 0.0$ \\
\hline 9 & 500.00 & $100.0 \pm 0.0$ & $85.0 \pm 0.0$ & $55.0 \pm 0.5$ & $80.0 \pm 0.0$ & $80.0 \pm 0.0$ & $0.0 \pm 0.0$ \\
\hline 10 & 1000.00 & $100.0 \pm 0.0$ & $100.0 \pm 0.0$ & $100.0 \pm 0.0$ & $90.0 \pm 0.0$ & $100.0 \pm 0.0$ & $0.0 \pm 0.0$ \\
\hline
\end{tabular}

TABLE-2

RELATIVE TOXICITY OF FIVE ESSENTIAL OILS AGAINST $C x$. quinquefasciatus (L.) AFTER 24 H OF TREATMENT

\begin{tabular}{|c|c|c|c|c|c|c|}
\hline \multirow{2}{*}{ Essential oils } & \multirow{2}{*}{$\mathrm{LC}_{50}(\mathrm{ppm})$} & \multirow{2}{*}{$95 \%$ Confidence limits (ppm) } & \multicolumn{4}{|c|}{ Fit of Probit lines } \\
\hline & & & Slope \pm SE & $\mathrm{X}^{2}$ & $\mathrm{df}$ & $\mathrm{P}$ \\
\hline Turpentine & 63.8 & $402.530-1558.19$ & $1.58 \pm 0.18$ & 8.31 & 6,3 & $\mathrm{P}<0.0001$ \\
\hline P. harmala & 85.91 & $533.45-2171.53$ & $1.58 \pm 0.18$ & 3.22 & 7,2 & $\mathrm{P}<0.0001$ \\
\hline C. nucifera & 338.58 & $974.461-3502.82$ & $2.49 \pm 0.39$ & 7.96 & 5,4 & $\mathrm{P}<0.0001$ \\
\hline A. indica & 207.56 & $905.52-3805.24$ & $1.87 \pm 0.25$ & 1.68 & 6,3 & $\mathrm{P}<0.0001$ \\
\hline E. citriodora & 165.51 & 554.68-1704.06 & $2.30 \pm 0.31$ & 1.89 & 6,3 & $\mathrm{P}<0.0001$ \\
\hline
\end{tabular}


was $0,0,0,0,0,10,15,25,55$ and $100 \%$ at concentrations of $1.95,3.90,7.81,15,62,31.25,62.50,125.00,250.00,500.00$ and 1000.00 ppm, respectively. The $\mathrm{LC}_{50}$ value (Table-2) for CX. quinquefasciatus (Say) was 338.58 with lower and upper $95 \%$ confidence limits as 974.461 and 3502.82 respectively. Analysis of variance revealed that concentrations of $C$. nucifera oil tested against $C x$. quinquefasciatus (Say) were significantly different among all treatments $(\mathrm{F}=1315.37$, df $=5,4 ; \mathrm{p}<$ 0.0001).

Azadirachta indica oil treatment: Table-1 revealed the percentage mortality of larvae of $C x$. quinquefasciatus (Say) when exposed to different concentrations of $A$. indica oil. The $\%$ mortality for $C x$. quinquefasciatus (Say) after $24 \mathrm{~h}$ of treatment was $0,0,0,5,5,15,30,55,80$ and $90 \%$ at concentrations of $1.95,3.90,7.81,15,62,31.25,62.50,125.00,250.00,500.00$ and $1000.00 \mathrm{ppm}$, respectively. The $\mathrm{LC}_{50}$ value for $C x$. quinquefasciatus (Say) was 207.56 with lower and upper $95 \%$ confidence limits as 905.52 and 3805.24, respectively. Analysis of variance revealed that concentrations of $A$. indica oil tested against $C x$. quinquefasciatus (Say) were significantly different among all treatments $(\mathrm{F}=336.63, \mathrm{df}=6,3 ; \mathrm{p}<0.0001)$.

Eucalyptus citriodora oil treatment: Similarly from Table-1, it was revealed that percentage mortality of larvae of $C x$. quinquefasciatus (Say) when exposed to different concentrations of $E$. citriodora oil. The \% mortality for $C x$. quinquefasciatus (Say) after $24 \mathrm{~h}$ of treatment was 0, 0, 0, 0, 5, 20, 40, 65,80 and $100 \%$ at concentrations of $1.95,3.90,7.81,15,62$, $31.25,62.50,125.00,250.00,500.00$ and $1000.00 \mathrm{ppm}$, respectively. The $\mathrm{LC}_{50}$ value (Table-2) for Cx. quinquefasciatus (Say) was 165.51 with lower and upper $95 \%$ confidence limits as 554.68 and 1704.06, respectively. Analysis of variance revealed that concentrations of $E$. citriodora oil tested against CX. quinquefasciatus (Say) were significantly different among all treatments $(\mathrm{F}=4258.53, \mathrm{df}=6,3 ; \mathrm{p}<0.0001)$.

From results, it was revealed that in control unit all larvae survived even at the end of the experiment.

All the essential oils tested demonstrated significant larvicidal activity on $C x$. quinquefasciatus (Say), with $\mathrm{LC}_{50}$ values ranging from 63.8 to $338.58 \mathrm{ppm}$. The exposure time is very important in determining the $\mathrm{LC}_{50}$ values in tested oils. Results (Table-1) showed that all oils give $100 \%$ mortality at 1000 ppm except $A$. indica which showed $90 \%$ mortality at $1000 \mathrm{ppm}$. As far as the effectiveness if oil is concerned, the results are significantly different for different essential oils. As seen from the Table-1 Turpentine oil was considered highly toxic as it was capable of killing $100 \%$ larvae of $C x$. quinquefasciatus after $24 \mathrm{~h}$ of treatment at concentration of $1000 \mathrm{ppm}$. Table-1 shows efficacy of Turpentine oil against $C x$. quinquefasciatus (Say) at different concentrations and have $\mathrm{LC}_{50}$ value 63.8. After Turpentine next effective oil was $P$. harmala. The $\mathrm{LC}_{50}$ value for $C x$. quinquefasciatus is 85.91 . As compared to $P$. harmala, $E$. citriodora has a greater $\mathrm{LC}_{50}$ value (165.51). More concentration of Eucalyptus is required to kill $50 \%$ of population as compared to P. harmala oil. Regarding A. indica and C. nucifera, they showed some delayed toxicity but effective with $\mathrm{LC}_{50}$ values 207.56 and 338.58, respectively. All the essential oils selected showed larvicidal effectiveness. Nevertheless upon a comparison of lethal concentrations as determining factor in the larvicidal effectiveness of essential oils, it is apparent that their biological effectiveness differs. So, according to the larvicidal activity of essential oils against Cx. quinquefasciatus (Say), the oils were arranged in the following ascending order of preference i.e. Tupentine $>P$. harmala $>$ E. citriodora $>A$. indica $>C$. nucifera

Various studies also suggested that plant oils are effective alternative against pests. Abbassi et al. ${ }^{11}$ demonstrated toxicity of the seed extract on different mosquito species. Comparing total mortality percentages of $P$. harmala acetonic seed extract on different treatments gives a good insight about its bioactivity.

The present work suggests, however, that products based on these essential oils may contribute greatly to a reduction in environment chemicalisation and to an overall reduction of the population density of some significant vectors such as $C x$. quinquefasciatus (Say). Supplementary investigations for the mode of constituents actions, effects on non-target organisms and old evaluation are necessary. These results obtain in the current study are useful in th discovery of more selective, biodegradable and naturally produced larvicidal compounds.

\section{Conclusion}

Essential oils from E. citriodora, $P$. harmala, A. indica, C. nucifera and Turpentine were tested against mosquito species $C x$. quinquefasciatus (Say) to develop biopesticide as an alternative to chemical insecticides. From the results it was concluded that turpentine has highest larvicidal properties. All the essential oils produced gave significant mortality and give $100 \%$ mortality at 1000 ppm except neem oil which gives $90 \%$ mortality at $1000 \mathrm{ppm}$. This study also revealed that all the essential oils used in the study have remarkable larvicidal properties. Present findings suggest that essential oils may be explored as a potential environmental benign larvicide.

\section{REFERENCES}

1. R. Pavela, Ind. Crops Prod., 30, 311 (2009).

2. M.W. Service, in eds.: R.P. Lane and R.W. Crosskey, Mosquitoes (Culicidae) In: Medical Insects and Arachnids, Chapman and Hall, London, pp: 723 (1993).

3. C.A. Lima, W.R. Almeida, H. Hurd and C.M. Albuquerque, Mem. Inst. Oswaldo Cruz, 98, 217 (2003).

4. D.C. Chavasse and H.H. Yap, Chemical Methods for Control of Vectors and Pests of Public Health Importance. Geneva, Switzerland, pp. 2427 (1997).

5. M.D. Moretti, G. Sanna-Passino, S. Demontis and E. Bazzoni, J. Pharm. Sci. Technol., 3, 13 (2002).

6. H. Cetin, Y. Kurt, K. Isik and A. Yanikoglu, Pharm. Biol., 47, 665 (2009).

7. S.Q. Liu, J.J. Shi, H. Cao, F.B. Jia, X.Q. Liu and G.L. Shi, in ed.: Dianmol, Survey of Pesticidal Component in Plant. In: Entomology in China in $21^{\text {st }}$ Century, Proceedings of 2000 Conference of Chinese Entomological Society, Science and Technique Press, Beijing, China, pp. 10981104 (2000).

8. R.D. Xue, D.R. Barnard and A. Ali, Med. Vet. Entomol.,15, 374 (2001).

9. M. Mohtar, M.A. Yarmo and A. Kadri, J. Trop. Forest Products, 5, 87 (1999).

10. R.N. Singh and B. Saratchandra, Caspian J. Environ. Sci., 3, 1 (2005).

11. K. Abbassi, Z. Atay-Kadiri and S. Ghaout, Physiol. Entomol., 28, 232 (2003). 